\title{
Apexification of Immature Necrotic Tooth with MTA using Platelet Rich Fibrin as an Internal Matrix
}

\author{
${ }^{1}$ Pradnya Vilas Bansode, ${ }^{2}$ Seema Pathak, ${ }^{3}$ Manthara Wavdhane, ${ }^{4}$ Shirish Khedgikar
}

\begin{abstract}
If dental pulp injury occurs in immature tooth, root development is halted producing several complications. There are a number of protocols to manage nonvital open-apex teeth. Platelet-rich fibrin (PRF) is widely used to accelerate soft and hard tissue healing which can be used as matrix. A 21-year-old male reported with the chief complaint of broken, discolored tooth, occasional pain, swelling and pus discharge in upper front region. Based on the clinical and radiologic findings the diagnosis of chronic periapical abscess with open apex with 11 was made. On first visit, triple antibiotic paste was placed in canal. On second visit after 21 days PRF was placed in periapical region over which mineral trioxide aggregate (MTA) plug was placed. On follow-up visit after 6 months, tooth was asymptomatic and nontender.
\end{abstract}

Keywords: Dental pulp injury, Open-apex tooth, Apexification, MTA, Platelet rich fibrin.

Key messages: This article presents a novel case report about the use of PRF as an autogenous, cost-effective and resorbable internal matrix prior to placement of MTA as an apical barrier.

How to cite this article: Bansode PV, Pathak S, Wavdhane M, Khedgikar S. Apexification of Immature Necrotic Tooth with MTA using Platelet Rich Fibrin as an Internal Matrix. Int J Prosthodont Restor Dent 2014;4(3):96-99.

Source of support: Nil

Conflict of interest: None

\section{INTRODUCTION}

Traumatic injuries sustained before closure of the apex often results in immature pulpless teeth. Apexification is defined as a method to induce a calcified barrier in a root with an open apex or the continued apical development of an incompletely formed root in teeth with necrotic pulp tissue. ${ }^{1}$ Apart from allowing compaction of the root filling material, the goal of this treatment also includes obtaining an apical barrier to prevent the passage of toxins and bacteria into the periapical tissues from the root canal.

\footnotetext{
${ }^{1}$ Professor and Head, ${ }^{2}$ Associate Professor

${ }^{3,4}$ Assistant Professor

${ }^{1-4}$ Department of Conservative Dentistry and Endodontics Government Dental College, Aurangabad, Maharashtra, India
}

Corresponding Author: Pradnya Vilas Bansode, Professor and Head, Department of Conservative Dentistry and Endodontics Government Dental College, Aurangabad, Maharashtra, India Phone: 9421679094, e-mail: dr.pradnya_mds@rediffmail.com
Mineral trioxide aggregate (MTA) is an FDA approved, commercially available material that has evoked considerable interest as a root end filling material. Lemon $^{2}$ advocated the use of an internal matrix when the perforation diameter is larger than $1 \mathrm{~mm}$ to avoid extrusion of the sealing material. The use of a matrix is advisable since its placement in the area of bone destruction provides a base on which the sealing material, like MTA, can be placed and packed. Several materials have been recommended to create an internal matrix, including calcium hydroxide, hydroxyapatite, resorbable collagen, calcium sulfate and decalcified freeze dried bone allograft (DFDBA).

This article presents a novel case report about the use of platelet rich fibrin (PRF) as an autogenous, costeffective and resorbable internal matrix prior to placement of MTA as an apical barrier.

\section{CASE HISTORY}

A 21 years old male reported to the department of conservative dentistry with the chief complaint of broken, discolored tooth, occasional pain, swelling and pus discharge in upper front region (Fig. 1). Dental history revealed trauma 10 years back. Radiograph revealed thin root dentinal walls and open apex with 11 (Fig. 2). Medical history of the patient was noncontributory. Based on the clinical and radiologic findings, the diagnosis of chronic periapical abscess with open apex with 11 was made and the treatment was undertaken in three visits.

\section{CLINICAL PROCEDURE}

\section{First Visit}

Under local anesthesia (to avoid patient discomfort) and rubber dam isolation, access opening was done on 11. Minimal instrumentation was done with \#100 K-file (Produits Dentaires, SA, Swiss) to remove intracanal debris and necrotic tissue. ${ }^{3}$ The triple antibiotic paste (1:1:1 mixture of ciprofloxacin, metronidazole and minocycline) was introduced inside the canal using $19 \mathrm{G}$ needle and syringe with stopper adjusted $1 \mathrm{~mm}$ short of apex. The paste was introduced till the CEJ level and the access cavity was sealed with temporary sealing material (MDTemp, Meta). Triple antibiotic paste was placed for the period of 21 days for canal disinfection. 


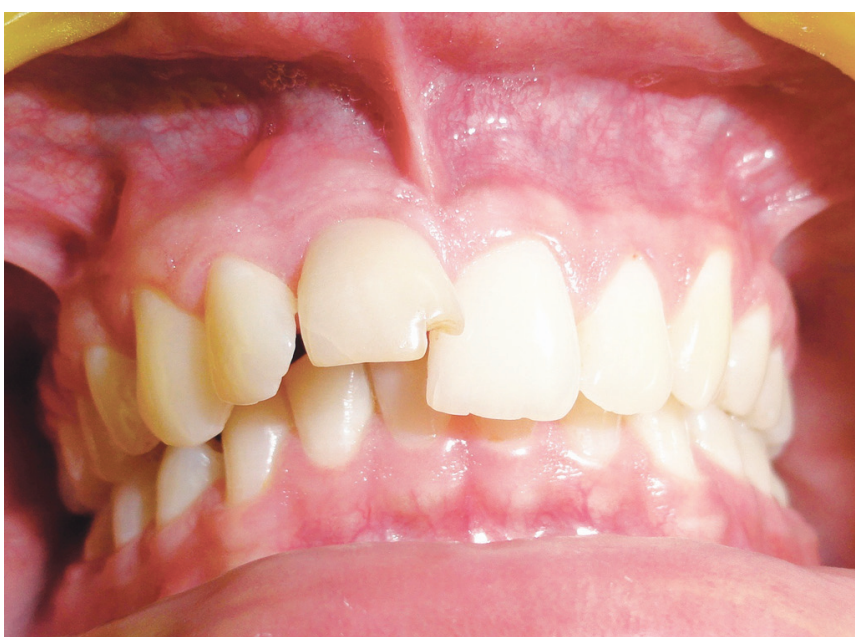

Fig. 1: Preoperative clinical view

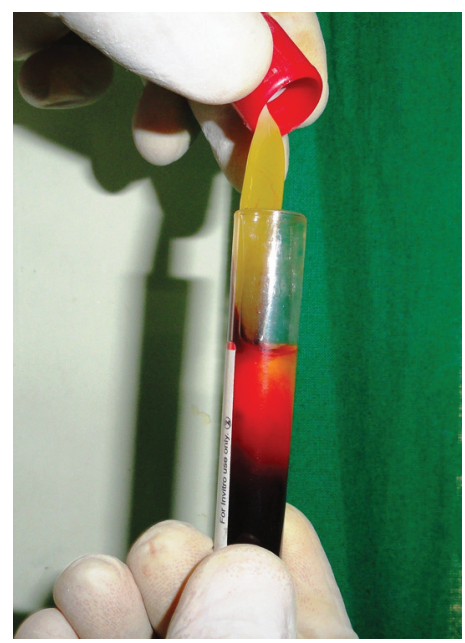

Fig. 3: Formed PRF after centrifuging blood

\section{Second Visit}

On recall examination, patient was totally asymptomatic and tooth no. 11 was nontender to percussion.

\section{Placement of PRF in the Periapical Region through the Canal}

Platelet rich fibrin was prepared from patient's own blood (Fig. 3). Local anesthesia was administered to avoid the patient discomfort/pain during placement of PRF in periapical region. Multiple small pieces of PRF were done with the help of sterile scissor to facilitate its placement into the apical region. Minute amount of MTA powder (MTA-Angelus, Londrina, Brazil) was sprinkled on the fibrin pieces to provide radiopacity for visualizing the placement of PRF (Fig. 4). PRF was then carried and condensed with plugger under radiovisiography guidance (Fig. 5). A 4 to $5 \mathrm{~mm}$ apical plug of MTA was placed (Fig. 6). Moistened cotton pellet was placed directly over the MTA and the access cavity was sealed with temporary cement for 24 hours to allow setting of MTA.

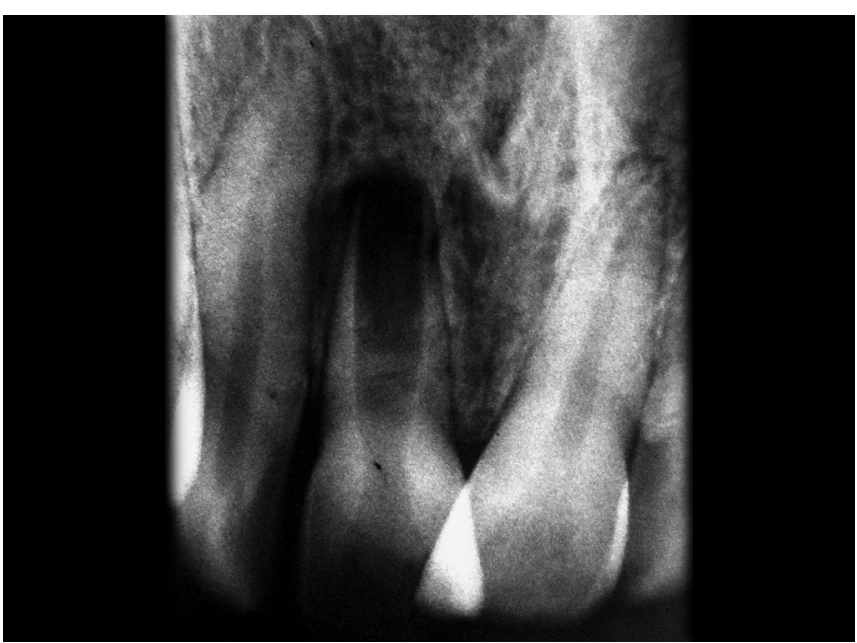

Fig. 2: Preoperative radiographic view

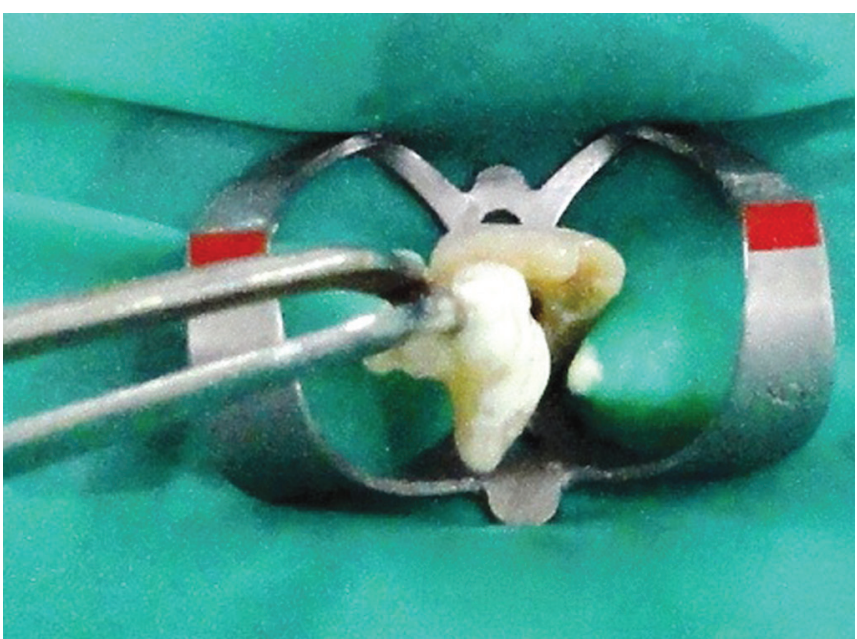

Fig. 4: Placement of PRF

\section{Third Visit}

After 24 hours, setting of MTA was confirmed and canal was obturated with thermoplastic obturation technique (E\&Q Plus Meta). Access opening was sealed with posterior composite resin (considering fracture susceptibility of tooth). ${ }^{4}$ Patient was rescheduled for evaluation after 6 months clinically (Fig. 7) and radiographically (Fig. 8), at which the tooth was asymptomatic and nontender patient did not return for next follow-up visits.

\section{DISCUSSION}

A number of methods have been recommended for artificial apical closure of open apex tooth. For a long time, calcium hydroxide has been used as an apexification material. The newly developed MTA has also been shown to be effective in artificial root-end closure. Both materials were found to stimulate the formation of mineralized tissue, thereby providing an adequate seal in the apical region. ${ }^{5}$ MTA, a biocompatible material, can be used to create a physical barrier that also helps in formation of bone and periodontium around its interface. ${ }^{6-8}$ 


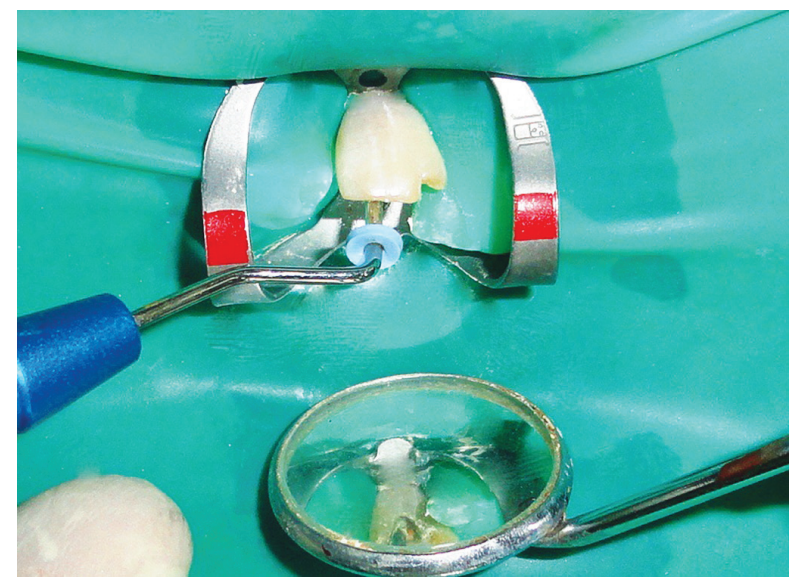

Fig. 5: Condensing PRF into root canal with endodontic plugger

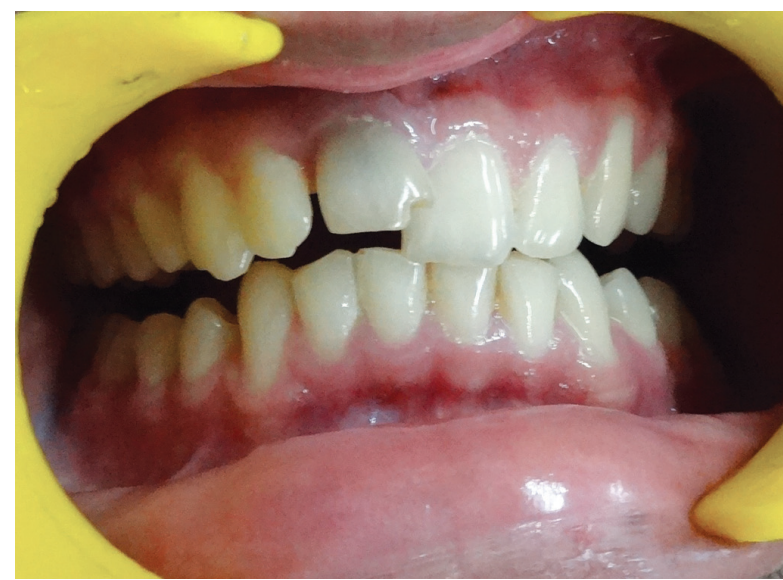

Fig. 7: Six months follow-up clinical photograph

We used triple antibiotic paste for complete disinfection of root canal owing to its high efficacy suggested by Hoshino et al. ${ }^{9-11}$ A large volume of the extruded material may set before it disintegrates and get resorbed. This might result in the persistence of the inflammatory process, which may complicate or even prevent repair of the tissue. ${ }^{12}$ PRF is a second generation platelet concentrate widely used to accelerate soft and hard tissue healing. Its advantages over the better known PRP includes ease of preparation/application, minimal expense, and no necessity of biochemical modification (no bovine thrombin or anticoagulant is required). ${ }^{13}$ PRF is a strictly autologous fibrin matrix containing a large quantity of platelet and leukocyte cytokines. PRF selectively binds, localizes cells and undergoes biodegradation over time. The platelet cytokines (PDGF, TGF- $\beta$, IGF-1) are gradually released as the fibrin matrix is resorbed, thus creating perpetual process of healing. ${ }^{14}$ PRF stimulates collagen production, recruits other cells to the site of injury, produces anti-inflammatory agents, initiates vascular in growths, induces cell differentiation, controls the local inflammatory response, and improves soft and hard tissue wound healing. The use of PRF as an alternative

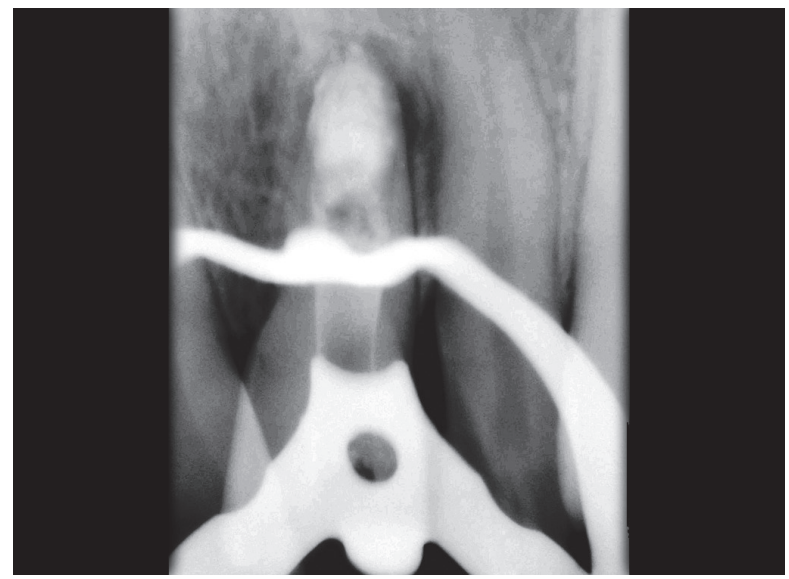

Fig. 6: Radiograph taken immediately postoperative after MTA plug placement

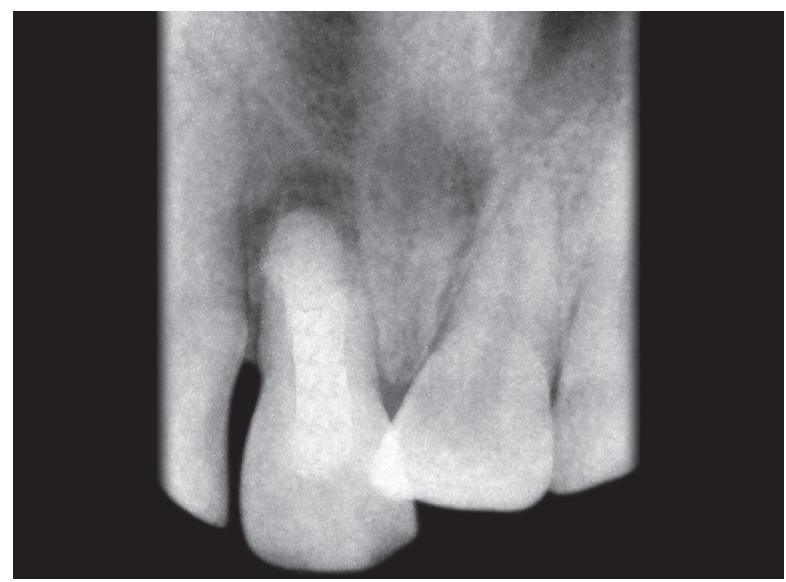

Fig. 8: Six months follow-up radiograph

source for a fibrin clot might have several advantages, including increased concentration of growth factors and removal of erythrocytes that would be expected to undergo necrosis shortly after clot formation. ${ }^{15}$ Thus in apexification procedures, use of PRF can be considered as a biological internal matrix rather than just a mechanical matrix in terms of healing and host tissue response.

Long-term observation of this case and randomized prospective clinical trials are needed to compare the use of PRF with that of other materials, as an internal matrix, to determine clinical outcomes of this procedure.

\section{REFERENCES}

1. American Association of Endodontists: Glossary of Endodontic Terms. Chicago, IL: American Association of Endodontists; 2003.

2. Lemon RR. Nonsurgical repair of perforation defects. Internal matrix concept. Dental Clinics of North America 1992;36: 439-457.

3. Felippe WT, Felippe MC, Rocha MJ. The effect of mineral trioxide aggregate on the apexification and periapical healing of teeth within complete root formation. Int Endo J 2006;39(1):2-9.

4. Katebzadeh N, Dalton C, Trope M. Strengthening Immature teeth during and after apexification. J Endod 1998;24(4): 256-259. 
5. Holden DT, Schwartz SA, Kirkpatrick TC, Schindler WG. Clinical outcomes of artificial root-end barriers with mineraltrioxide aggregate in teeth with immature apices. J Endod 2008;34(7):812-817.

6. Economides N, Pantelidou O, Kokkas A, Tziafas D. Short-term periradicular tissue response to mineral trioxide aggregate (MTA) as root-end filling material. Int Endod J 2003;36:44-48.

7. Torabinejad M, Watson TF, Pitt Ford TR. Sealing ability of a mineral trioxide aggregate when used as a root end filling material. J Endod 1993;19:591-595.

8. Felippe WT, Felippe MC, Rocha MJ. The effect of mineral trioxide aggregate on the apexification and periapical healing of teeth with incomplete root formation. Int Endod J 2006; 39(1):2-9.

9. Hoshino E, Kurihara-Ando N, Sato I, Uematsu H, Sato M, Kota K, et al. In vitro antibacterial susceptibility of bacteria taken from infected root dentine to a mixture of ciprofloxacin, metronidazole and minocycline. Int Endod J 1996;29(2):125-130.

10. Sato I, Ando-Kurihara N, Kota K, Iwaku M, Hoshino E. Sterilization of infected root-canal dentine by topical application of a mixture of ciprofloxacin, metronidazole and minocycline in situ. Int Endod J 1996;29(2):118-124.

11. Windley W 3rd, Teixeira F, Levin L, Sigurdsson A, Trope M. Disinfection of immature teeth with a triple antibiotic paste. J Endod 2005;31(6):439-443.

12. Holland R, Mazuqueli L, Souza V, Murata SS, Dezan E Jr. Influence of the type of vehicle and limit of obturation on apical and periapical tissue response in dogs teeth after root canal filling with mineral trioxide aggregate. J Endod 2007;33(6):693-697.

13. Torabinejad M, Turman M. Revitalization of tooth with necrotic pulp and open apex by using platelet-rich plasma: a case report. J Endod 2011;37(2):265-268.

14. Simonpieri A, Del Corso M, Sammartino G, Dohan Ehrenfest DM. The relevance of choukroun's platelet-rich fibrin and metronidazole during complex maxillary rehabilitations using bone allograft. Part I: A New Grafting Protocol. Implant Dent 2009;18(2):102-111.

15. Hargreaves KM, Geisler T, Henry M, Wang Y. Regeneration potential of the young permanent tooth: what does the future hold? J Endod 2008;34(7 Suppl):S51-S56. 